\title{
Growth in glucose-based medium and exposure to subinhibitory concentrations of imipenem induce biofilm formation in a multidrug-resistant clinical isolate of Acinetobacter baumannii Elisabetta Nucleo1, Laura Steffanoni ${ }^{2}$, Giulia Fugazza1,2, Roberta Migliavacca1 ${ }^{1}$ Ernesto Giacobone ${ }^{3}$, Antonella Navarra ${ }^{4}$, Laura Pagani ${ }^{1}$ and Paolo Landini*2
}

Address: ${ }^{1}$ Department of Morphological, Eidological and Clinical Sciences, Università di Pavia, Pavia, Italy, ${ }^{2}$ Department of Biomolecular Sciences and Biotechnology, Università degli Studi di Milano, Milano, Italy, ${ }^{3}$ Microbiological Analysis Laboratory, IRCCS Fondazione San Matteo Hospital, Pavia, Italy and ${ }^{4}$ Microbiological Analysis Laboratory IRCCS Fondazione S Maugeri Hospital, Pavia, Italy

Email: Elisabetta Nucleo - elisabetta.nucleo@unipv.it; Laura Steffanoni - laura.steffanoni@studenti.unimi.it;

Giulia Fugazza - giulia.fugazza@unipv.it; Roberta Migliavacca - r.miglia@unipv.it; Ernesto Giacobone - microbiologia@smatteo.pv.it;

Antonella Navarra - navarra@fsm.it; Laura Pagani - laura.pagani@unipv.it; Paolo Landini* - paolo.landini@unimi.it

* Corresponding author

Published: 22 December 2009

BMC Microbiology 2009, 9:270 doi:I0.1 I86/I47I-2180-9-270

This article is available from: http://www.biomedcentral.com/l47I-2180/9/270

(C) 2009 Nucleo et al; licensee BioMed Central Ltd.

This is an Open Access article distributed under the terms of the Creative Commons Attribution License (http://creativecommons.org/licenses/by/2.0), which permits unrestricted use, distribution, and reproduction in any medium, provided the original work is properly cited.

\begin{abstract}
Background: Acinetobacter baumannii is emerging as an important nosocomial pathogen. Multidrug resistance, as well as ability to withstand environmental stresses, makes eradication of $A$. baumannii difficult, particularly from hospital settings.

Results: Over a six-year period, 73 isolates of $A$. baumannii were collected from infected patients in two hospitals in Italy. While 69 out of the 73 isolates displayed identical multidrug antibiotic resistance pattern, they were susceptible to carbapenems. Genetic profiles of these 69 isolates, determined by Pulsed Field Gel Electrophoresis (PFGE), indicated that they were genetically related and could be clustered in a specific clone, called SMAL. We tested the ability of the SMAL clone to form biofilm, an important determinant for bacterial colonization of the human host and for persistence in the hospital environment. Biofilm formation by A. baumannii SMAL, measured as surface adhesion to polystyrene, is strongly affected by growth conditions, being impaired in rich growth media such as LB, while being favoured in glucose-based medium. Surface adhesion in glucose-based media is inhibited by treatment with cellulase, suggesting that it depends on production of cellulose or of a chemically related extracellular polysaccharide. Exposure of $A$. baumannii SMAL to subinhibitory concentrations of imipenem resulted in biofilm stimulation and increased production of iron uptake proteins. Growth in iron-supplemented medium also stimulated surface adhesion, thus suggesting that increased intracellular iron concentrations might act as an environmental signal for biofilm formation in A. baumannii SMAL.
\end{abstract}

Conclusions: Our results indicate that exposure to subinhibitory concentrations of imipenem can stimulate biofilm formation and induce iron uptake in a pathogenic strain of $A$. baumannii, with potential implications on antibiotic susceptibility and ability to persist in the human host. 


\section{Background}

Bacteria belonging to the genus Acinetobacter, in particular Acinetobacter baumannii and the closely related Acinetobacter 13 TU and gen.sp. 3 (referred to as Acinetobacter baumannii sensu lato), are important opportunistic pathogens in hospital-acquired infections (reviewed in [1]).

A. baumannii can cause pneumonia, wound infections, urinary tract infections, bacteremia, and meningitis $[2,3]$. The hospital environment can represent an important reservoir for A. baumannii during nosocomial infections; in particular, patients in long-term care facilities can be colonized by A. baumannii and carry the bacterium for long periods with no visible symptoms [1]. Ability to persist in the hospital environment is related to multidrug resistance $[1,4]$, which allows $A$. baumannii to survive prolonged antimicrobial therapy in hospitalized patients. Multidrug resistance in A. baumannii clinical isolates is mediated by a variety of mechanisms, such as modification of target sites, efflux pumps, enzymatic inactivation of antibiotics, etc. (reviewed in [1]). Carbapenems (e.g. imipenem) have been used as antibiotics of choice for treatment of $A$. baumannii infections, but increasing resistance to these antimicrobial agents mediated by $\beta$-lactamases of the B and D classes is undermining this option [4$8]$.

In addition to multidrug resistance, A. baumannii is able to withstand environmental stresses such as exposure to detergents [9] and desiccation [10], which can contribute to its persistence in the hospital environment. Biofilm formation is considered an important factor in resistance to stresses and in bacterial colonization and persistence in different environmental niches [11]. It has been reported that ability of $A$. baumannii to form biofilm in laboratory conditions correlates with resistance to complementmediated bacterial killing [12]. This observation suggests that biofilm formation can contribute to A. baumannii survival during host infection, thus representing an important virulence factor. In contrast, studies addressing possible correlation between biofilm and multidrug resistance have produced conflicting results [13-16]. Ability to form biofilm has been reported for numerous $A$. baumannii strains [12-16], and several biofilm determinants, i.e., the csu pili [17], and the outer membrane-associated proteins Bap [18] and OmpA [19] have been identified.

In this report, we have characterized A. baumannii isolates responsible for nosocomial infections in two hospitals in Italy. We showed that all isolates were genetically related, suggesting that they originate from a single clone, termed SMAL. A. baumannii SMAL is not clonally related to known multidrug resistant $A$. baumannii lineages such as European clones I and II $[20,21]$. We have studied how growth conditions and exposure of A. baumannii SMAL to subinhibitory concentrations of imipenem affects its ability to form biofilm, a cellular process with important consequences on sensitivity to antimicrobial agents and on microbial persistence in the human host.

\section{Results \\ Characterization of Acinetobacter baumannii clinical isolates}

A total of 73 Acinetobacter baumannii isolates responsible of various infections were collected from patients in different wards of two Hospitals in Pavia, Italy, between 2002 and 2007. 69 out of 73 isolates showed identical multidrug resistant phenotype, being resistant to fluoroquinolones, aminoglycosides, and most $\beta$-lactams; however, they retained susceptibility to carbapenems, tetracycline and to ampicillin/sulbactam (Table 1). The remaining 4 isolates showed different antibiotic susceptibility patterns, including resistance to carbapenems and tetracycline (data not shown). The 69 isolates were characterized by an identical $\beta$-lactamase pattern, producing 3 distinct $\beta$-lactamases, with pI values of $6.1,7.0,>8.2$, compatible with those of OXA-10, OXA-51-like and AmpC-type enzymes. PCR experiments and direct DNA sequencing using the same primers confirmed the presence of $b l a_{\text {OXA-10 }}$ and $b l a_{\text {OXA-90 }}$ genes (Table 1 ). The $\beta$-lactamase pattern shown by the isolates is consistent with their susceptibility to carbapenems: indeed, OXA-51-like $\beta$ lactamases only possess slow hydrolytic activity against imipenem and result in very little effect on imipenem sensitivity even when overexpressed [22].

Genomic DNA was extracted from every A. baumannii isolate, digested with ApaI restriction endonuclease, and analysed by PFGE. The dendrogram clearly revealed that all 69 A. baumannii isolates showing identical multidrug resistant phenotype displayed more than $80 \%$ similarity, with differences in DNA patterns never exceeding 3 DNA restriction fragments. A comparison of a selection of isolates with strains RUH875 and RUH134, representative of European clones I and II, is shown in Figure 1. Our results indicate that, according to the criteria and the cut-off value defined, all isolates belong to the same clone, which was called SMAL, from the hospitals and locations where it had caused outbreaks most frequently (S. Matteo/S. Maugeri Hospitals Acute care and Long term care facilities). PFGE experiments indicate that the great majority of isolates belong to a main clonal SMAL subtype, showing $100 \%$ genetic similarity, while a smaller number of isolates display a level of genetic relatedness with the SMAL main clonal subtype not lower than $83.5 \%$, defining the clonal subtypes SMAL 1, 2, 3, and 4 (Table 1).

A. baumannii strains are notorious for causing recurrent hospital outbreaks, and a few lineages achieve epidemic 
Table I: Antimicrobial susceptibility, production of $\beta$-lactamases, and pulsotype of the 69 isolates of $A$. baumannii analyzed in this study.

\begin{tabular}{|c|c|c|c|c|c|c|c|c|c|c|c|c|c|c|c|c|c|c|}
\hline \multirow[b]{2}{*}{$\begin{array}{l}\text { Number of } \\
\text { isolates }\end{array}$} & \multirow[b]{2}{*}{ Hospital } & \multirow[b]{2}{*}{$\begin{array}{l}\text { Sample } \\
\text { Source }\end{array}$} & \multirow[b]{2}{*}{ Ward/unita } & \multicolumn{12}{|c|}{ MIC Method Phoenix $(\mu \mathrm{g} / \mathrm{ml})^{b}$} & \multirow[b]{2}{*}{$\begin{array}{l}\text { MIC IP } \\
(\mu \mathrm{g} / \mathbf{m l})\end{array}$} & \multirow[b]{2}{*}{$\begin{array}{c}\beta- \\
\text { lactamases }\end{array}$} & \multirow[b]{2}{*}{ Pulsotype } \\
\hline & & & & TE & $\mathbf{A} / \mathbf{S}$ & Cl & AK & GM & $\mathbf{P P}$ & PT & AT & $\mathbf{C Z}$ & $\mathbf{C P}$ & IP & $\mathbf{M P}$ & & & \\
\hline 2 & S. Matteo & Blood & Medicine & $\leq 2$ & $8 / 4$ & $>2$ & $>32$ & $>8$ & $>64$ & $>64 / 4$ & $>16$ & $>32$ & $>16$ & $\leq 1$ & $\leq \mathrm{I}$ & $0.5-1.0$ & $\begin{array}{l}\text { AmpC, OXA- } \\
90, \text { OXA-10 }\end{array}$ & SMAL \\
\hline 6 & S. Matteo & Sputum & Medicine & $\leq 2$ & $8 / 4$ & $>2$ & $>32$ & $>8$ & $>64$ & $>64 / 4$ & $>16$ & $>32$ & $>16$ & $\leq 1$ & $\leq \mathrm{l}$ & $0.5-1.0$ & $\begin{array}{l}\text { AmpC, OXA- } \\
90, \text { OXA-10 }\end{array}$ & SMAL \\
\hline 2 & S. Matteo & Urine & Medicine & 4 & 1 & $>2$ & $>32$ & $>8$ & $>64$ & $>64 / 4$ & $>16$ & $>16$ & I & 2 & $\leq \mathrm{I}$ & $0.5-1.0$ & $\begin{array}{l}\text { AmpC, OXA- } \\
90, \text { OXA-10 }\end{array}$ & SMAL \\
\hline 6 & S. Matteo & $\begin{array}{l}\text { Soft tissue } \\
\text { swab }\end{array}$ & Medicine & 4 & $8 / 4$ & $>2$ & $>32$ & $>8$ & $>64$ & $>64 / 4$ & $>16$ & $>16$ & $>16$ & $\leq 1$ & $\leq \mathrm{I}$ & $0.5-1.0$ & $\begin{array}{l}\text { AmpC, OXA- } \\
90, \text { OXA-10 }\end{array}$ & $\begin{array}{l}\text { SMAL, } \\
\text { SMAL 2, }\end{array}$ \\
\hline 3 & S. Matteo & $\begin{array}{l}\text { Bronchoaspi } \\
\text { rate }\end{array}$ & Medicine & I & $8 / 4$ & $>2$ & $>32$ & $>8$ & $>64$ & $>64 / 4$ & $>16$ & $>16$ & $>16$ & $\leq 1$ & $\leq \mathrm{I}$ & $0.5-1.0$ & $\begin{array}{l}\text { AmpC, OXA- } \\
90, \text { OXA-10 }\end{array}$ & $\begin{array}{l}\text { SMAL, } \\
\text { SMAL } 3\end{array}$ \\
\hline 3 & S. Matteo & Urine & Surgery & 4 & 1 & $>2$ & $>32$ & $>8$ & $>64$ & $>64 / 4$ & $>16$ & $>16$ & I & 2 & $\leq \mathrm{I}$ & $0.5-1.0$ & $\begin{array}{l}\text { AmpC, OXA- } \\
90, \text { OXA-10 }\end{array}$ & SMAL \\
\hline 8 & S. Matteo & $\begin{array}{l}\text { Wound } \\
\text { swab }\end{array}$ & Surgery & $\leq 2$ & $8 / 4$ & $>2$ & $>32$ & $>8$ & $>64$ & $>64 / 4$ & $>16$ & $>16$ & $>16$ & $\leq 1$ & $\leq \mathrm{I}$ & $0.5-1.0$ & $\begin{array}{l}\text { AmpC, OXA- } \\
90, \text { OXA-10 }\end{array}$ & SMAL \\
\hline 8 & S. Matteo & Blood & Surgery & I & 1 & $>2$ & $>32$ & $>8$ & $>64$ & $>64 / 4$ & $>16$ & $>16$ & I & 2 & $\leq \mathrm{I}$ & $0.5-1.0$ & $\begin{array}{l}\text { AmpC, OXA- } \\
90, \text { OXA-10 }\end{array}$ & $\begin{array}{l}\text { SMAL, } \\
\text { SMAL I }\end{array}$ \\
\hline 1 & S. Matteo & Pus & Surgery & $\leq 2$ & $8 / 4$ & $>2$ & $>32$ & $>8$ & $>64$ & $>64 / 4$ & $>16$ & $>16$ & $>16$ & $\leq 1$ & $\leq \mathrm{I}$ & 1 & $\begin{array}{l}\text { AmpC, OXA- } \\
90, \text { OXA-10 }\end{array}$ & SMAL \\
\hline 1 & S. Matteo & Sputum & Surgery & I & $4 / 2$ & $>2$ & $>32$ & $>8$ & $>64$ & $64 / 4$ & $>16$ & $>16$ & $>16$ & $\leq 1$ & $\leq \mathrm{I}$ & 1 & $\begin{array}{l}\text { AmpC, OXA- } \\
90, \text { OXA-10 }\end{array}$ & SMAL \\
\hline 1 & S. Matteo & $\begin{array}{l}\text { Soft tissue } \\
\text { swab }\end{array}$ & LTCU & $\leq 2$ & 1 & $>2$ & $>32$ & $>8$ & $>64$ & $64 / 4$ & $>16$ & $>16$ & $>16$ & $\leq 1$ & $\leq \mathrm{I}$ & 1 & $\begin{array}{l}\text { AmpC, OXA- } \\
90, \text { OXA-10 }\end{array}$ & SMAL \\
\hline 1 & S. Matteo & Sputum & LTCU & I & I & $>2$ & $>32$ & $>8$ & $>64$ & $64 / 4$ & $>16$ & $>16$ & $>16$ & 2 & $\leq \mathrm{I}$ & 1 & $\begin{array}{l}\text { AmpC, OXA- } \\
90, \text { OXA-10 }\end{array}$ & SMAL \\
\hline 1 & S. Matteo & Blood & LTCU & I & 1 & $>2$ & 32 & $>8$ & $>64$ & $64 / 4$ & $>16$ & $>16$ & $>16$ & $\leq 1$ & $\leq \mathrm{I}$ & 1 & $\begin{array}{l}\text { AmpC, OXA- } \\
90, \text { OXA-10 }\end{array}$ & SMAL \\
\hline 2 & S. Matteo & $\begin{array}{l}\text { Soft tissue } \\
\text { swab }\end{array}$ & Dermatology & $\leq 2$ & 1 & $>2$ & $>32$ & $>8$ & $>64$ & $>64 / 4$ & $>16$ & $>16$ & $>16$ & $\leq 1$ & $\leq \mathrm{I}$ & $0.5-1$ & $\begin{array}{l}\text { AmpC, OXA- } \\
90, \text { OXA-10 }\end{array}$ & SMAL \\
\hline
\end{tabular}


Table I: Antimicrobial susceptibility, production of $\beta$-lactamases, and pulsotype of the 69 isolates of $A$. baumannii analyzed in this study. (Continued)

\begin{tabular}{|c|c|c|c|c|c|c|c|c|c|c|c|c|c|c|c|c|c|c|}
\hline I & S. Matteo & Pus & Dermatology & $\leq 2$ & $8 / 4$ & $>2$ & $>32$ & $>8$ & $>64$ & $>64 / 4$ & $>16$ & $>16$ & $>16$ & $\leq \mathrm{I}$ & $\leq$ & 1 & $\begin{array}{c}\text { AmpC, OXA- } \\
90, \text { OXA-10 }\end{array}$ & SMAL \\
\hline 2 & S. Matteo & $\begin{array}{l}\text { Wound } \\
\text { swab }\end{array}$ & Ambulatory & 1 & 1 & $>2$ & $>32$ & $>8$ & $>64$ & $>64 / 4$ & $>16$ & $>16$ & $>16$ & 4 & 2 & 2 & $\begin{array}{c}\text { AmpC, OXA- } \\
90, \text { OXA-10 }\end{array}$ & SMAL \\
\hline I & S. Matteo & Urine & Ambulatory & $\leq 2$ & 1 & $>2$ & $>32$ & $>8$ & $>64$ & $>64 / 4$ & $>16$ & $>16$ & I & $\leq \mathrm{I}$ & $\leq \mathrm{I}$ & 1 & $\begin{array}{c}\text { AmpC, OXA- } \\
90, \text { OXA-10 }\end{array}$ & SMAL \\
\hline 2 & S. Matteo & $\begin{array}{l}\text { Wound } \\
\text { swab }\end{array}$ & Urology & $\leq 2$ & 1 & $>2$ & $>32$ & $>8$ & $>64$ & $>64 / 4$ & $>16$ & $>16$ & $>16$ & $\leq 1$ & $\leq 1$ & 0.5 & $\begin{array}{c}\text { AmpC, OXA- } \\
90, \text { OXA-10 }\end{array}$ & SMAL \\
\hline 2 & S. Matteo & Urine & Nephrology & I & I & $>2$ & $>32$ & $>16$ & $>64$ & $>64 / 4$ & $>16$ & $>16$ & 1 & $\leq \mathrm{I}$ & $\leq 1$ & 1 & $\begin{array}{c}\text { AmpC, OXA- } \\
90, \text { OXA-10 }\end{array}$ & SMAL \\
\hline I & S. Matteo & Blood & Haematology & 8 & 1 & $>2$ & $>32$ & $>8$ & $>64$ & $>64 / 4$ & $>16$ & $>16$ & 16 & $\leq \mathrm{I}$ & $\leq 1$ & 1 & $\begin{array}{c}\text { AmpC, OXA- } \\
90, \text { OXA-10 }\end{array}$ & SMAL \\
\hline I & S. Maugeri & $\begin{array}{l}\text { Bronchoaspi } \\
\text { rate }\end{array}$ & PRU & 8 & 1 & $>2$ & $>32$ & $>8$ & $>64$ & $>64 / 4$ & $>16$ & $>16$ & l & $\leq 1$ & $\leq 1$ & 1 & $\begin{array}{l}\text { AmpC, OXA- } \\
90, \text { OXA-10 }\end{array}$ & SMAL \\
\hline 7 & S. Maugeri & Urine & NRU & I & I & $>2$ & $>32$ & $>8$ & $>64$ & $64 / 4$ & $>16$ & $>16$ & I & $\leq \mathrm{I}$ & $\leq \mathrm{I}$ & 1 & $\begin{array}{c}\text { AmpC, OXA- } \\
90, \text { OXA- } 10\end{array}$ & SMAL \\
\hline 2 & S. Maugeri & Skin swab & NRU & 1 & $8 / 4$ & $>2$ & $>32$ & $>8$ & $>64$ & $>64 / 4$ & $>16$ & $>16$ & $>16$ & $\leq 1$ & $\leq \mathrm{I}$ & 0.5 & $\begin{array}{c}\text { AmpC, OXA- } \\
90, \text { OXA-10 }\end{array}$ & SMAL \\
\hline I & S. Maugeri & $\begin{array}{l}\text { Bronchoaspi } \\
\text { rate }\end{array}$ & NRU & $\leq 2$ & 1 & $>2$ & $>32$ & $>8$ & $>64$ & $64 / 4$ & $>16$ & $>32$ & 1 & $\leq 1$ & $\leq 1$ & $0.5-1$ & $\begin{array}{c}\text { AmpC, OXA- } \\
90, \text { OXA-10 }\end{array}$ & SMAL \\
\hline I & S. Maugeri & Urine & ORU & $\leq 2$ & $8 / 4$ & $>2$ & $>32$ & $>8$ & $>64$ & $>64 / 4$ & $>16$ & $>32$ & I & $\leq \mathrm{I}$ & $\leq \mathrm{I}$ & 0.5 & $\begin{array}{c}\text { AmpC, OXA- } \\
90, \text { OXA-10 }\end{array}$ & SMAL \\
\hline I & S. Maugeri & Skin swab & ORU & $\leq 2$ & $8 / 4$ & $>2$ & $>32$ & $>8$ & $>64$ & $64 / 4$ & $>16$ & $>32$ & 1 & $\leq \mathrm{I}$ & $\leq 1$ & 0.5 & $\begin{array}{c}\text { AmpC, OXA- } \\
90, \text { OXA-10 }\end{array}$ & SMAL \\
\hline 2 & S. Maugeri & Urine & FRU & $\leq 2$ & $8 / 4$ & $>2$ & $>32$ & $>8$ & $>64$ & $>64 / 4$ & $>16$ & $>32$ & $>16$ & $\leq \mathrm{I}$ & $\leq \mathrm{I}$ & 0.5 & $\begin{array}{c}\text { AmpC, OXA- } \\
90, \text { OXA- } 10\end{array}$ & SMAL \\
\hline
\end{tabular}

a PRU, pulmonary rehabilitation unit; NRU, neurological rehabilitation unit; ORU, oncological rehabilitation unit. b TE, tetracicline; $A / S$, ampicillin/sulbactam; Cl, ciprofloxacin; AK, amikacin; GM, gentamicin; PP, piperacillin; PT, piperacillin/tazobactam; AT, aztreonam; CZ, ceftazidime; CP, cefepime; IP, imipenem; MP, meropenem. Ditto marks indicate that the $\beta$-lactamase pattern was identical for all the strains tested. 


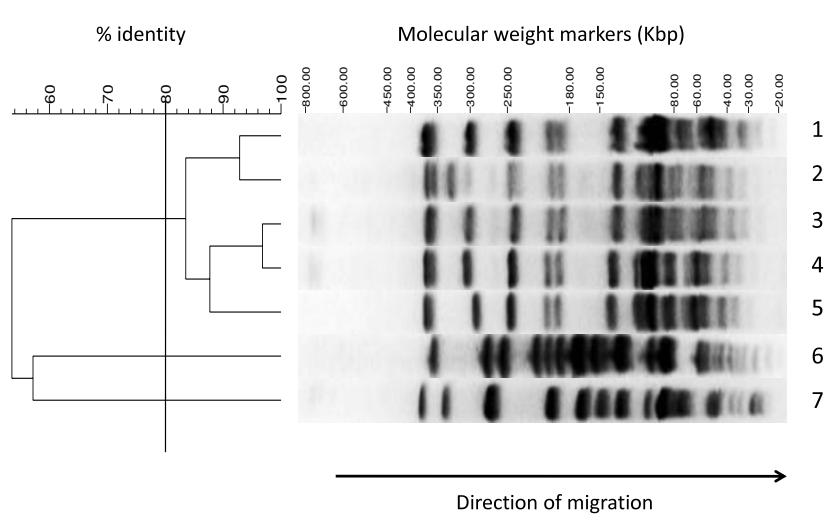

Figure I

PFGE profiles of $A$. baumannii genomes after digestion with Apal restriction nuclease (Lanes I-7, top to bottom). 5 of the 69 isolates identified in this study and analyzed by PFGE are shown (Lanes I-5). Lane I, Isolate from urine sample (see Table I, line 22); Lane 2: Isolate from soft tissue swab (Table I, line 4); Lane 3: Isolate from blood sample (Table I, line 8); Lane 4: Isolate from wound swab (Table I, line 7); Lane 5: Isolate from bronchoaspirate sample (Table I, Line 5). Isolates were compared to strains representative of European clones I (RUH875, Lane 7) and II (RUHI34, Lane 6). Strains belonging to the same clone are clustered at a level of $80 \%$ by PFGE with the parameters used as shown by the dendrogram analysis shown on the left.

status, reaching multiple hospitals or communities [23]. Examples include European clones I and II, widespread in continental Europe, and clone III, which is however less relevant in terms of clinical and epidemiological importance $[20,21]$. The SMAL clone seems to define a novel lineage of $A$. baumannii, as suggested by significant differences in antibiotic resistance pattern (e.g. sensitivity to tetracycline) in comparison to European Clones I and II $[20,21]$. Lack of genetic relatedness was further confirmed by PFGE experiments, which only showed $57 \%$ relatedness between the SMAL clone and isolates belonging to European Clones I and II (Figure 1). Multiplex PCR performed using ompA, $c s u E$, and $b l a_{\text {OXA-51 }}$-like as target genes [24] confirmed these differences (data not shown).

\section{Biofilm formation by $A$. baumannii clinical isolates}

The A. baumannii isolates belonging to the SMAL clone were tested for their ability to form biofilm, measured as surface adhesion to polystyrene microtiter plates. Biofilm growth is considered an important factor for host colonization $[25,26]$ and for resistance to environmental and cellular stresses [11]. Ability to form biofilm, measured as surface adhesion to polystyrene microtiter plates, was very similar for all A. baumannii isolates tested (data not shown); results shown throughout the paper refer to the A. baumannii isolate described in Line 22 of Table 1 . This isolate was considered representative of the A. baumannii
SMAL clone since it belongs to the main genotypic subgroup of the SMAL clone (Figure 1) and since it was the first $A$. baumannii to be isolated in this survey. Surface adhesion to microtiter plates by A. baumannii SMAL clone was determined in various growth conditions, comparing two growth temperatures $\left(30^{\circ} \mathrm{C}\right.$ vs. $\left.37^{\circ} \mathrm{C}\right)$, and different growth media: the rich peptone-based LB medium, LB medium diluted 1:4 (LB1/4), the M9Glu/sup medium [[27], described in Methods], and the M9Suc/sup in which $0.2 \%$ sucrose was added as main carbon source instead of glucose. LB1/4 was tested since it was shown to promote production of adhesion factors in other Gram negative bacteria, such as Escherichia coli [28]. We found that biofilm formation by $A$. baumannii SMAL was strongly affected both by growth media and by temperature: indeed, while surface adhesion was very poor in LB medium at either $30^{\circ} \mathrm{C}$ or $37^{\circ} \mathrm{C}$, it was clearly stimulated by growth in LB $1 / 4$, although only at $30^{\circ} \mathrm{C}$. Finally, growth in M9Glu/sup resulted in efficient surface adhesion both at $30^{\circ} \mathrm{C}$ and at $37^{\circ} \mathrm{C}$, while growth in sucrosebased medium (M9Suc/sup) resulted in much lower levels (Figure 2A). The observation that growth temperature affects biofilm formation in the LB1/4, but not in sugarbased media such as M9Glu/sup, would suggest that this process could be mediated by different mechanisms and by different adhesion factors.

A major adhesion factor characterized in A. baumannii is represented by the $c s u$ pili described in the $A$. baumannii strain ATCC 19606 [17]. Thus, we measured by Real Time PCR relative expression of the $c s u C$ and $c s u E$ genes in different growth media. The csuC and csuE genes encode respectively a chaperone involved in pili assembly and the pilus major subunit. Expression of csu genes was hardly detectable in all growth conditions (data not shown). Consistent with this result, we could not detect any production of $c s u$ pili in A. baumannii SMAL by electron microscopy, regardless of growth conditions (Figure 3 and data not shown). This result would suggest that production of $\operatorname{csu}$ pili, and thus their contribution to surface adhesion, might be limited in this strain. In addition to csu pili, A. baumannii 19606 biofilm is characterized by efficient binding to Calcofluor [17], a fluorescent dye which binds specifically to cellulose and chitin; this observation suggests that cellulose, which is produced as an extracellular polysaccharide (EPS) in many bacteria [2932], might be a biofilm determinant in A. baumannii. To detect possible production of cellulose, we grew A. baumannii SMAL on different solid media supplemented with Calcofluor. Interestingly, Calcofluor binding was detected on M9Glu/sup solid medium, but not on M9Suc/sup or in either peptone-based media (LB or LB1/4), suggesting that growth on glucose induces production of Calcofluorbinding EPS in A. baumannii SMAL (Figure 2B). In order to test the possible role of this EPS as an adhesion factor, 


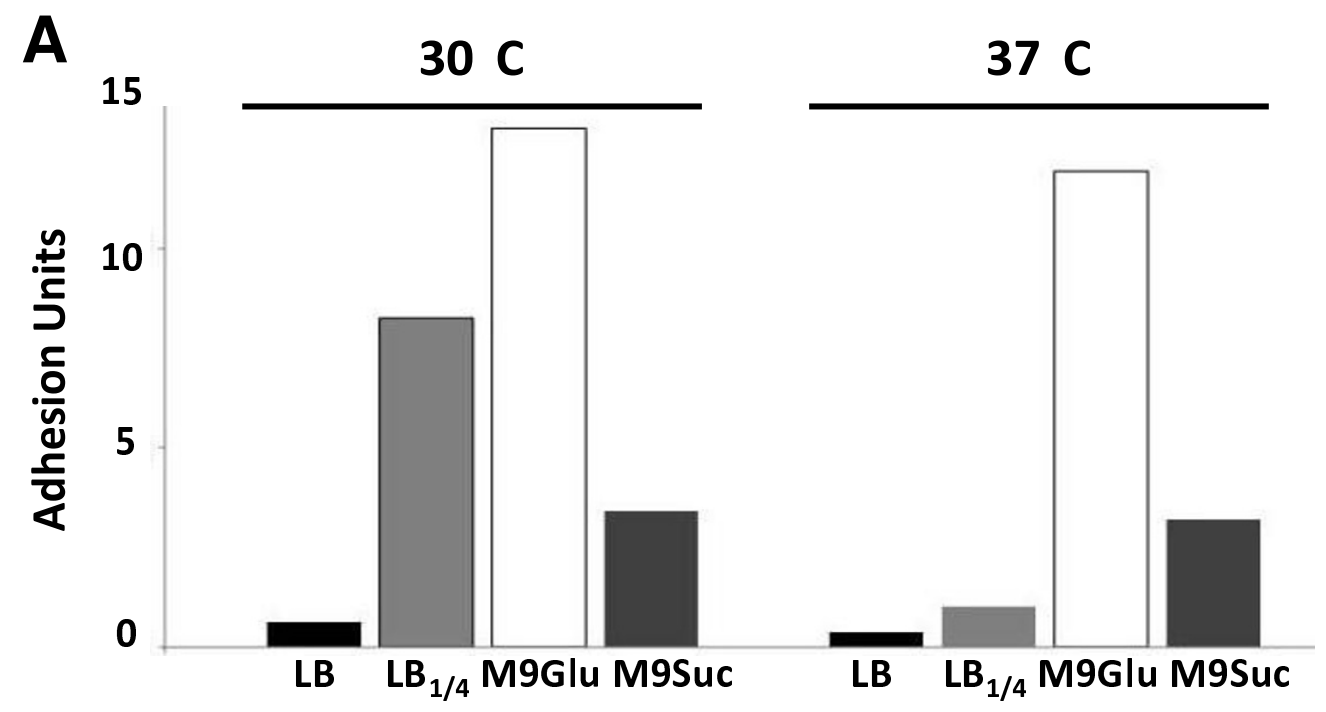

B

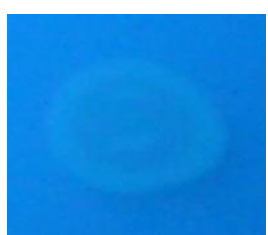

LB

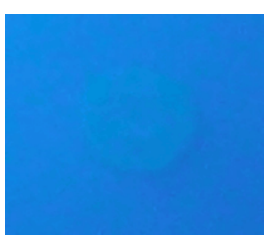

LB 1/4

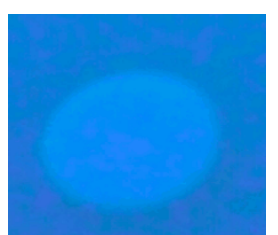

M9Glu/sup

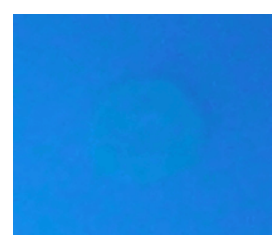

M9Suc/sup

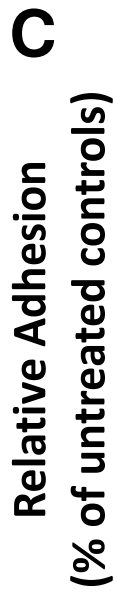

120

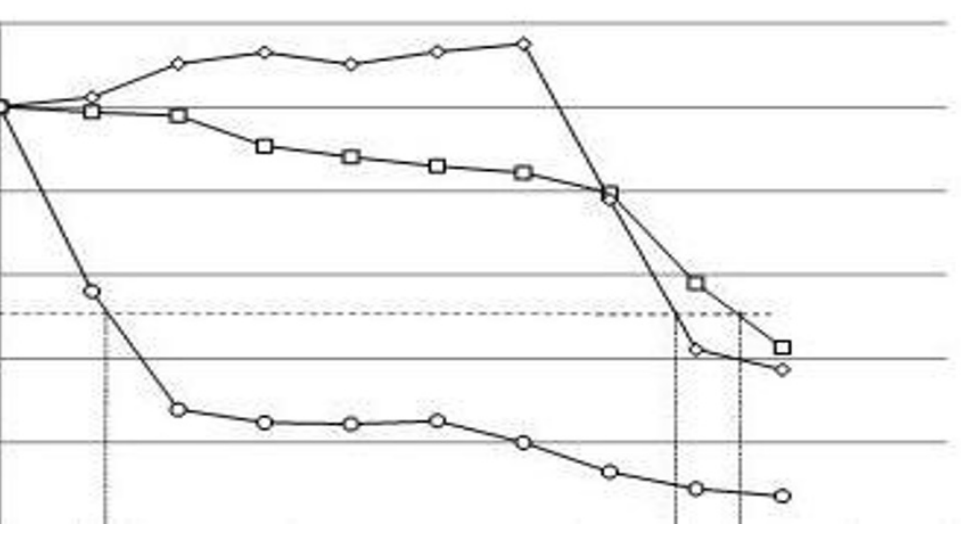

0.15

0.5

$5 \quad 12 \quad 19$

50

Cellulase (milliunits)

\section{Figure 2}

A. Surface adhesion to polystyrene microtiter plates by A. baumannii SMAL clone. Black bars bacterial cultures grown in LB medium; light grey bars LBI/4 medium; white bars M9Glu/sup; dark grey bars M9Suc/sup. B. Binding of Calcofluor to A. baumannii SMAL clone grown in solid media. C. Inhibition of A. baumannii biofilm formation by cellulase treatment: circles, M9Glu/sup medium; diamonds, M9Suc/sup medium; squares, LB I/4 medium. The horizontal dotted line indicates the $50 \%$ inhibition mark. $I C_{50}$ 's values are indicated by vertical dotted lines. 

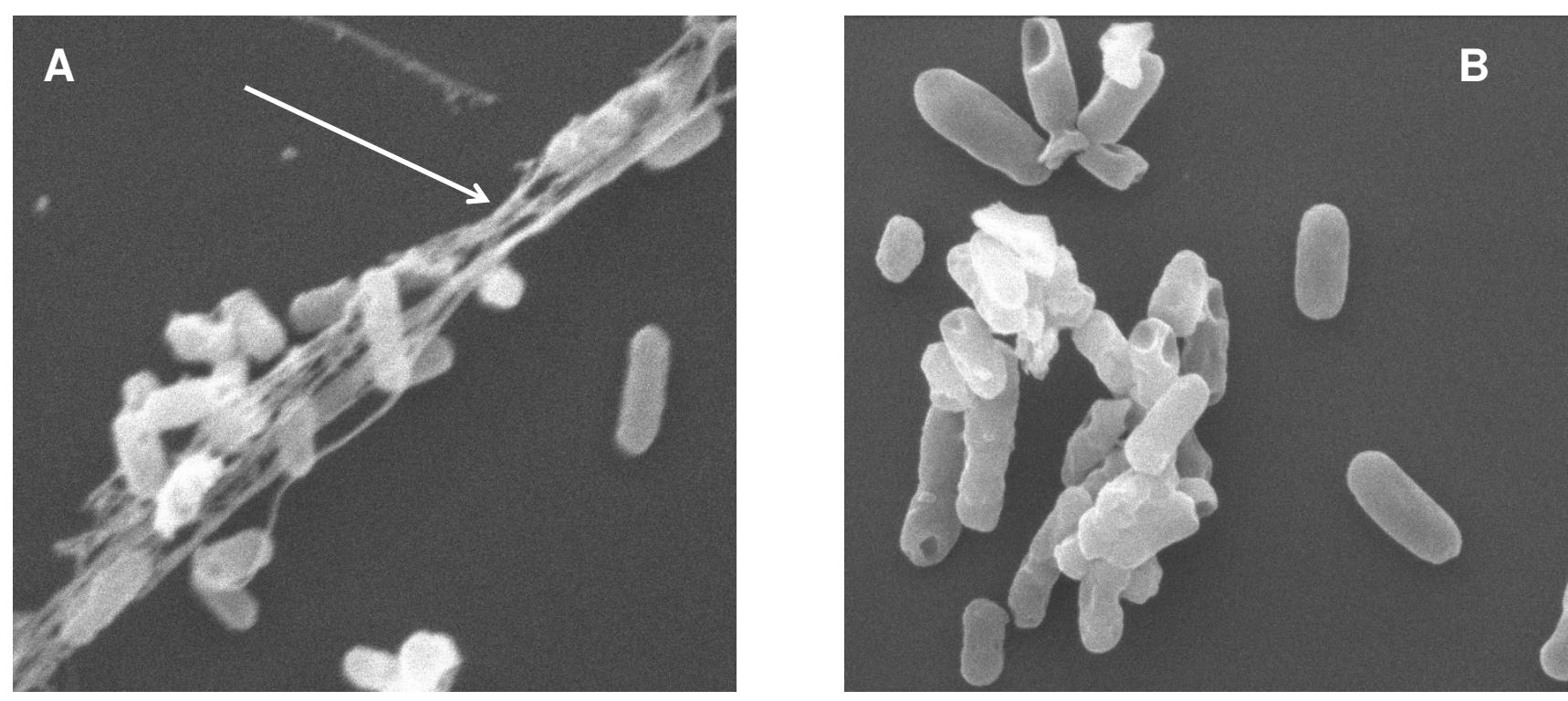

Figure 3

Transmission electron microscopy images of $A$. baumannii SMAL biofilm-forming cells. Panel A: A. baumannii cells resuspended from biofilm 10,000x magnification. The bundle-like fibers embedding the bacterial cells are indicated by the arrow. Panel B: A. baumannii cells resuspended from biofilm and treated with I Unit cellulase for 30 minutes, 12,000× magnification.

we tested surface adhesion to polystyrene in different growth media in the presence of the cellulose-degrading enzyme cellulase (Figure 2C). Surface adhesion was efficiently inhibited by low amounts of cellulase when $A$. baumannii SMAL was grown in M9Glu/sup (50\% inhibition at 0.15 Units cellulase, Figure 2C), thus suggesting that surface adhesion is mediated by cellulose production. In contrast, cellulase was only able to impair surface adhesion at much higher concentrations when A. baumannii SMAL was grown either in M9Suc/sup or in LB1/4 media (50\% inhibition at ca. 12 and 19 Units cellulase, respectively, Figure 2C). At these amounts of cellulase, inhibitory effects are likely due to non-specific effects such as changes in surface tension or other physico-chemical properties of the medium. Cellulase effects in LB medium were not tested due to the very inefficient biofilm formation in this medium (Figure 2A). To further verify the possible role of cellulose-related EPS as an adhesion factor, $A$. baumannii SMAL biofilm formed on microtiter plates by cells growing in M9Glu/sup medium was resuspended in $50 \mathrm{mM}$ phosphate buffer $\mathrm{pH} 6.0$ by vigorous pipetting and incubated 30 minutes either in the presence or in the absence of $1 \mathrm{U}$ cellulase prior to fixation with gluteraldehyde and visualization by transmission electron microscopy. Figure 3 shows that A. baumannii SMAL cells recovered from the biofilm appear embedded in bundlelike filaments (Panel 3A), which disappear upon cellulase treatment (Panel 3B), further confirming direct involvement of cellulose in cell-cell aggregation.
In addition to its role of adhesion factor, cellulose, as well as other EPS, can protect bacterial cells from environmental stresses such as desiccation and oxidative stress $[11,29]$. Thus, we tested the A. baumannii SMAL clone grown either in M9Glu/sup or in LB1/4 for resistance to desiccation and to challenge with $\mathrm{H}_{2} \mathrm{O}_{2}$. A. baumannii SMAL displayed high levels of resistance to both stresses, which was expected since this is a common feature for the Acinetobacter genus [1]; growth in different media did not significantly affect its resistance level (data not shown), suggesting that, in A. baumannii SMAL, cellulose production might be more related to surface adhesion than to resistance to environmental stresses.

\section{Exposure to subinhibitory concentrations of imipenem affects biofilm formation}

The A. baumannii SMAL clone is sensitive to carbapenems such as imipenem (Table 1 ). However, in many cases, imipenem treatments failed to eradicate the A. baumannii SMAL clone from patients, often resulting in relapses. We investigated the possibility that, although sensitive to imipenem in standard Minimal Inhibitory Concentration (MIC) determination assays, the A. baumannii SMAL clone might possess mechanisms of resistance or tolerance to this antibiotic. Exposure to subinhibitory concentrations of antibiotics can result in the induction of adaptive responses and in biofilm stimulation [33], which appears to increase tolerance to antibiotics via different molecular mechanisms (reviewed in [34]). Thus, we tested the effect 
of subinhibitory concentrations of imipenem on biofilm formation by A. baumannii SMAL: concentrations of imipenem ranging between 0.03 and $0.125 \mu \mathrm{g} / \mathrm{ml}$, which correspond respectively to $1 / 16$ and $1 / 4$ of the MIC of imipenem in M9Glu/sup medium, resulted in biofilm stimulation by up to 3 -fold, both at $30^{\circ} \mathrm{C}$ (Figure 4 ) and at $37^{\circ} \mathrm{C}$ (data not shown). Growth rate was not impaired by imipenem at any of the concentrations tested. In contrast, treatment of A. baumannii SMAL with subinhibitory concentrations of tetracycline did not result in any significant induction of biofilm formation (data not shown), suggesting that biofilm induction is a specific effect of imipenem. Since in M9Glu/sup medium surface adhesion by A. baumannii SMAL is mediated by cellulose production (Figure 2C), we tested whether imipenem-induced biofilm stimulation could be inhibited by treatment with cellulase. As shown in Figure 3, although cellulase did affect biofilm formation both in the presence and in the absence of imipenem, the extent of biofilm stimulation induced by the antibiotic is very similar (ca. 3-fold) regardless of the presence of cellulase. This observation seems to suggest that exposure to subinhibitory imipenem concentrations induce production of a cellulase-resistant adhesion factor. To understand if imipenem-dependent biofilm stimulation is specific for A. baumannii SMAL, we tested the effects of subinhibitory imipenem concentration on biofilm formation in A. baumannii strains RUH875 and RUH134, representative of European clones I and II. In the absence of imipenem, both strains could form biofilm to a similar extent as A. baumannii SMAL (data not shown). MICs of imipenem for RUH875 and RUH134 in

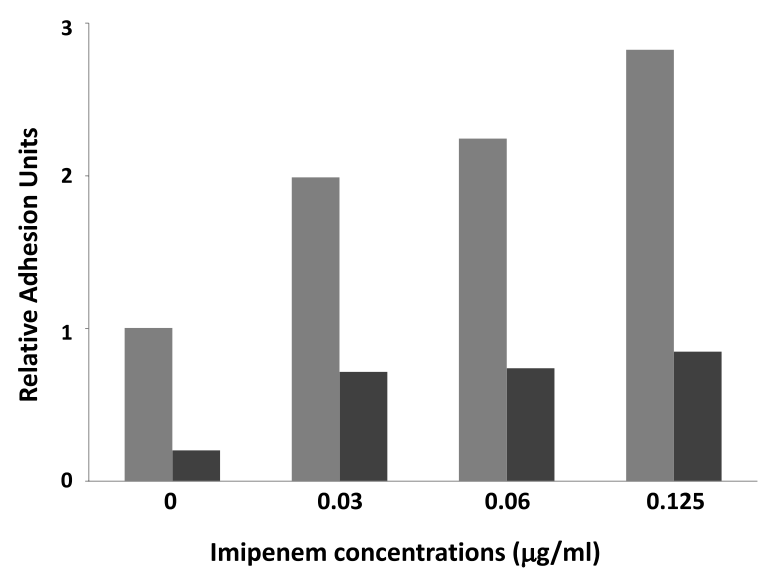

Figure 4

Surface adhesion by $A$. baumannii SMAL clone grown in $\mathrm{M9Glu} / \mathrm{sup}$ medium at $30^{\circ} \mathrm{C}$ in the presence of subinhibitory imipenem concentrations. Grey bars: untreated samples; black bars: samples treated with I Unit cellulase.
M9Glu/sup medium were 0.5 and $0.25 \mu \mathrm{g} / \mathrm{ml}$, again very similar to the MIC for A. baumannii SMAL. Unlike A. baumannii SMAL, however, exposure to subinhibitory concentrations of the antibiotic failed to stimulate surface adhesion in these strains (data not shown).

In order to identify possible imipenem-dependent biofilm determinants we compared the patterns of membrane-associated proteins of A. baumannii SMAL grown either in the absence or in the presence of $0.125 \mu \mathrm{g} / \mathrm{ml}$ imipenem (1/4 MIC). Exposure to subinhibitory imipenem concentrations clearly affected the intensity of a protein band with the apparent molecular weight of ca. 70 KDa (Figure 5). The $70 \mathrm{KDa}$ bands from both the control and the imipenem-treated samples were excised from the gel, and the proteins were digested with trypsin and identified through MALDI-TOF analysis as previously described [35]. The $70 \mathrm{KDa}$ bands were identified as a mixture of three polypeptides, all involved in metal uptake: the OprC protein, a copper receptor, was found both in control and imipenem-exposed bacterial cultures. In contrast, two proteins involved in iron uptake, a ferrichrome receptor protein and a TonB-dependent siderophore, were only found in the membrane of imipenem-exposed cultures (Table 2). We tested the possibil-

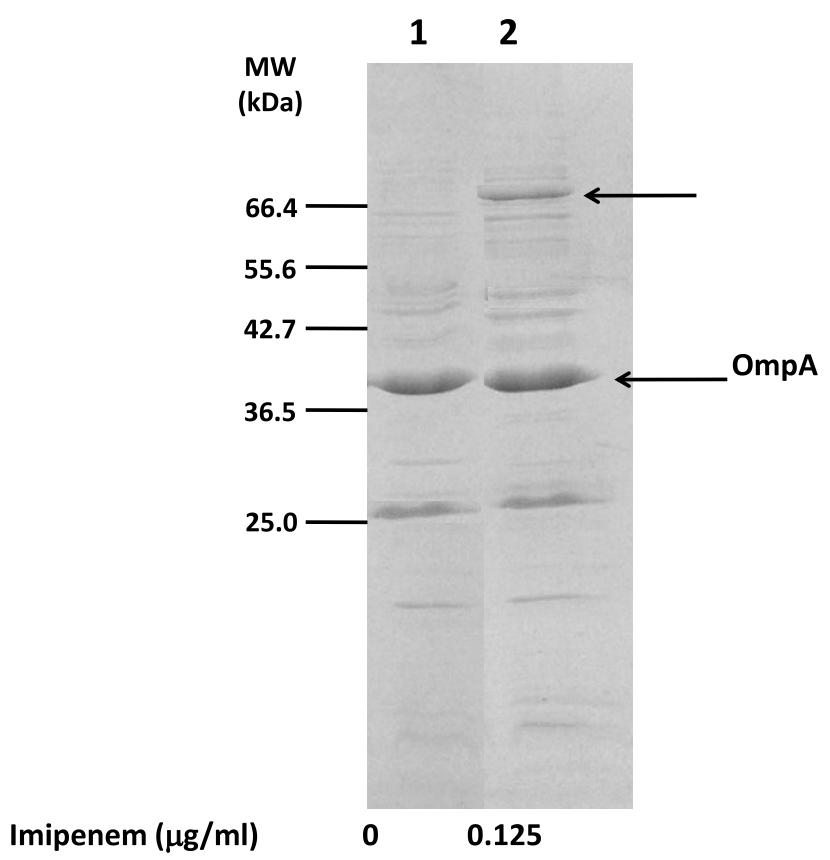

\section{Figure 5}

SDS-PAGE of membrane fractions of A. baumanni SMAL clone: the arrows point to the $70 \mathrm{KDa}$ bands showing different levels of expression in cultures treated with imipenem. The band at ca. $40 \mathrm{KDa}$ was identified by MALDITOF as OmpA the major outer membrane protein in A. baumannii. Molecular Weight standards are shown. 
Table 2: Identification of membrane proteins induced by exposure to subinhibitory imipenem concentrations.

\begin{tabular}{|c|c|c|c|c|}
\hline $\begin{array}{c}\text { Protein identified by } \\
\text { MALDI-TOF and/or } \\
\text { corresponding gene in } \\
\text { A. baumannii ATCC } \\
\text { I7978 }\end{array}$ & $\begin{array}{l}\text { Expected Molecular } \\
\text { Weight (KDa) }\end{array}$ & Protein function & $\begin{array}{l}\text { Conditions in which } \\
\text { proteins are produced }\end{array}$ & $\begin{array}{l}\text { Gene expression in the } \\
\text { presence of imipenem } \\
\text { (fold induction) }\end{array}$ \\
\hline OprC (AIS_0I70) & 67,700 & $\begin{array}{l}\text { Putative outer membrane } \\
\text { copper receptor }\end{array}$ & $\begin{array}{l}\text { Both in control and in } \\
\text { imipenem-induced cultures }\end{array}$ & N.D. \\
\hline (AIS_1921) & 71,742 & Ferrichrome-iron receptor & Imipenem-induced cultures & 3.51 \\
\hline (AIS_1063) & 73,034 & $\begin{array}{l}\text { TonB-dependent } \\
\text { siderophore receptor }\end{array}$ & Imipenem-induced cultures & 3.39 \\
\hline
\end{tabular}

Genes encoding the identified proteins are identified with the annotation number for A. baumanni ATCC 17978 strain [52].

ity that increased production of iron uptake proteins upon exposure to subinhibitory imipenem concentrations could be due to transcription activation of the corresponding genes. Relative transcription levels of the ferrichrome receptor protein- and the TonB-dependent siderophore-encoding genes were determined by Real Time PCR experiments, which showed that transcription of both genes is activated by $0.125 \mu \mathrm{g} / \mathrm{ml}$ imipenem $(1 / 4$ the MIC) by 3.5-fold (Table 2).

\section{Effects of iron on biofilm formation}

Our results indicate that subinhibitory imipenem concentrations positively affect both surface adhesion (Figure 4) and iron uptake (Figure 5, Table 2). In most bacteria, iron is an important environmental signal for production of adhesion factors and biofilm formation [36,37]. Thus, it is possible that biofilm stimulation by imipenem might depend upon higher intracellular iron concentration mediated by increased production of iron uptake proteins. To verify this hypothesis, we tested the effects of iron on surface adhesion by A. baumannii SMAL. Addition to the M9Glu/sup medium of $\mathrm{FeSO}_{4}$ at concentrations ranging between 2 and $50 \mu \mathrm{M}$ led to a 2.5 -fold stimulation of surface adhesion (Figure 6). Similar to what observed for subinhibitory imipenem concentrations, iron-dependent biofilm stimulation takes place even in the presence of cellulase, thus suggesting that it is not mediated by increased production of cellulose (Figure 6). We tested the possibility that biofilm stimulation either by iron or by subinhibitory imipenem concentrations could be mediated by increased expression of the piliencoding csu genes. However, Real Time PCR experiments showed no significant changes either in $\operatorname{csuC}$ or $c s u E$ transcription in response to exposure either to $0.125 \mu \mathrm{g} / \mathrm{ml}$ imipenem or to $50 \mu \mathrm{M} \mathrm{FeSO}_{4}$ (data not shown).

\section{Discussion}

In this work, we have reported the isolation and characterization of an A. baumannii strain responsible for outbreaks both in Acute Care and in Long-Term Care Facilities in two Italian hospitals. A. baumannii isolates showed a distinct antibiotic resistance pattern, being resistant to most aminoglycosides and $\beta$-lactams, but sensitive to carbapenems and tetracycline (Table 1). Analysis of the isolates by PFGE suggests that they belong to a single lineage, unrelated to A. baumannii European clones I and II (Figure 1). This A. baumannii clone, named SMAL (acronym of the hospitals and wards where it was isolated), was repeatedly isolated over a six-year period, and was able to cause different kinds of infections, ranging from urinary tract infections to bacteremia (Table 1), thus showing significant potential as pathogenic strain as well as ability to persist in the hospital environment.

Ability to form biofilm plays an important role both in survival within the host and in persistence of $A$. baumannii

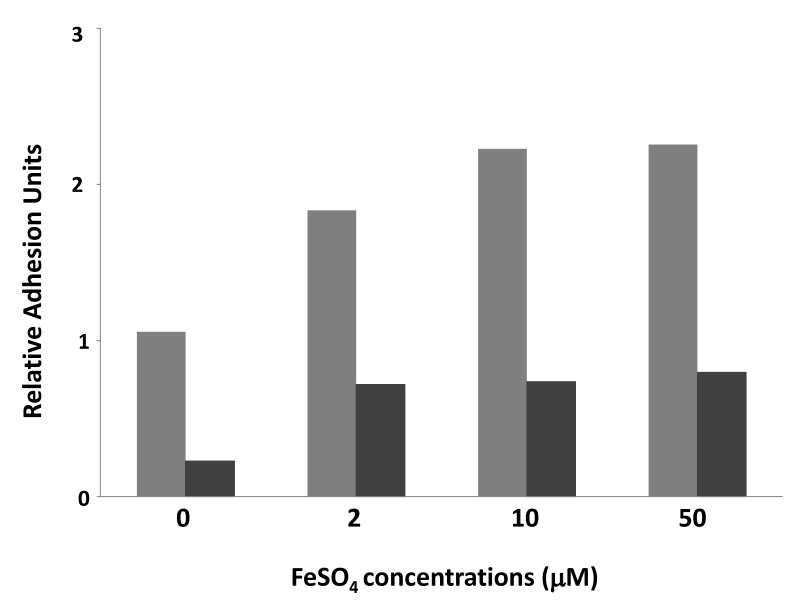

Figure 6

Surface adhesion by $A$. baumannii SMAL clone grown in $\mathrm{M9Glu} / \mathrm{sup}$ medium at $30^{\circ} \mathrm{C}$ in the presence of $\mathrm{FeSO}_{4}$. Grey bars: untreated samples; black bars: samples treated with I Unit cellulase. 
in hospital environments, thus leading to recurrent nosocomial infections [1]. Our results show that biofilm formation by the A. baumannii SMAL clone, measured as ability to adhere to polystyrene microtiter plates, is strongly affected by growth conditions, being inhibited in the rich, peptone-based, LB medium (Figure 2A). 1:4 dilution of the LB medium was enough to stimulate surface adhesion, which, however, was further increased by growth in glucose-based medium (Figure 2A). Biofilm stimulation by growth on glucose was also observed for strains RUH875 and RUH134, representative of epidemic European clones I and II (data not shown), in line with similar effects reported for the A. baumannii strain ATCC 19606 [17]. These observations strongly suggest that, to fully evaluate biofilm proficiency of $A$. baumannii clinical isolates, biofilm assays should be carried out, not only in peptone-based media, as reported in various studies [12$14]$, but also in glucose-based media. Binding to the fluorescent dye Calcofluor (Figure $2 \mathrm{~B}$ ) and biofilm sensitivity to cellulase (Figure 2C) strongly suggest that growth on glucose-based medium triggers production of cellulose, or possibly of an EPS containing a $\beta$-1,4-glucan portion. Initial attempts to identify the chemical nature of the EPS produced by A. baumannii SMAL would indeed suggest that its composition is very complex (data not shown). Production of a Calcofluor-binding EPS was not stimulated by sugars other than glucose, such as sucrose (Figure 2B), as well as lactose and arabinose (data not shown), thus suggesting that glucose is a specific inducer of EPS production. Identification of a $\beta$-1,4-glucan-containing EPS as an adhesion factor, and of its dependence on glucose, is relevant for the understanding of which biofilm determinants are produced by A. baumannii in different environments and in different body sites during host colonization. Indeed, glucose concentration in blood, but not in other A. baumannii infection sites such as in the urinary tract, are similar to the concentrations used in our experiments and would thus be able to induce EPS production. In addition to promoting cell adhesion, production of cellulose might contribute to protection from macrophage killing, a role proposed for other bacterial EPS such as alginate in P. aeruginosa [38]. We have identified putative glycosyltransferase-encoding genes in the $A$. baumannii SMAL genome that might be involved in EPS biosynthesis. However, attempts to inactivate genes possibly involved in EPS biosynthesis and to assess their role have not been successful so far.

Although A. baumannii SMAL clone is sensitive to imipenem in vitro (Table 1), treatments with this antibiotic often failed to clear the patients from infections (data not shown), thus suggesting that $A$. baumannii SMAL might show tolerance to imipenem during host infection. We investigated the possibility that $A$. baumannii SMAL sensitivity to imipenem might be affected by different growth conditions and/or by biofilm formation. MIC for imipenem in glucose-based medium was lower compared to the MIC in peptone-based growth media $(0.5 \mathrm{vs} .2 \mu \mathrm{g} / \mathrm{ml}$; data not shown), thus suggesting that biofilm formation in M9Glu/sup does not result in increased resistance to imipenem. However, exposure to subinhibitory imipenem concentrations $(0.03-0.125 \mu \mathrm{g} / \mathrm{ml})$ results in a 3fold stimulation of surface adhesion (Figure 4). Interestingly, imipenem-dependent biofilm stimulation appears to be distinctive for A. baumannii SMAL, since it was not observed in strains RUH875 and RUH134, representative of epidemic European clones I and II. It is likely that this specific response to imipenem might contribute to A. baumannii SMAL pathogenic and epidemic potential.

In addition, exposure to subinhibitory imipenem concentrations increased production of ferrichrome receptor protein and of TonB-like siderophore receptor protein, both involved in iron uptake (Figure 5, Table 2). Imipenemdependent increase in expression of iron uptake proteins is probably part of a more general response to a cellular stress, rather than being induced by an actual reduction in available iron by imipenem at the concentrations tested. Iron uptake proteins play a key role during host infection by various bacteria [39]; consistent with this function, pathogenic A. baumannii strains possess a large number of iron uptake genes in comparison to environmental isolates [40]. Induction of ferrichrome receptor and the TonB-like siderophore receptor proteins by imipenem appears to take place via transcription activation of the corresponding genes (Table 2). Thus, exposure to subinhibitory imipenem concentrations can trigger the production of both biofilm determinants and iron uptake proteins, in what appears to be a co-ordinated response to cellular stresses. Direct connection between iron uptake and biofilm formation is also suggested by the observation that increased $\mathrm{FeSO}_{4}$ concentrations in the growth medium can act as a positive environmental signal for surface adhesion in the A. baumannii SMAL clone (Figure 6). Our results suggest that neither cellulose nor csu pili are responsible for iron-dependent increase in surface adhesion: interestingly, a recent report shows that adherence to human airway epithelial cell is independent of csu pili [41], thus suggesting that important adhesion and virulence factors of $A$. baumannii are yet to be identified.

\section{Conclusions}

In the present study we have characterized a novel multidrug-resistant, pathogenic strain of A. baumannii (A. baumannii SMAL clone). We have highlighted the importance of environmental signals such as glucose and iron availability for biofilm formation by this strain. Our results suggest that exposure to subinhibitory imipenem concentrations stimulates iron uptake, which in turn leads to an increased production of adhesion factors and bio- 
film formation. Induction of biofilm formation by subinhibitory antibiotic concentration, even when it does not directly result in increased antibiotic resistance in vitro, can nonetheless protect bacteria against killing by antimicrobials during host infection [33,42]. Understanding of the molecular mechanism of imipenem-induced biofilm formation could provide useful information for the design of more effective protocols in antimicrobial therapy.

\section{Methods \\ Bacterial identification}

A total of 69 A. baumannii non-replicated isolates, recovered between 2002 and 2007 from patients in medical, surgical and long-term care wards, were included in the study. Isolates were collected in two different hospitals in Pavia, Italy: the "I.R.C.C.S. Fondazione S. Maugeri", a LongTerm Care Facility, and the "I.R.C.C.S. Fondazione S. Matteo", an Acute Care Hospital. The isolates were initially identified using the automatic systems Vitek 2 (BioMérieux, Marcy-l'Etoile, France) and Phoenix (Becton Dickinson, Sparks, MD). Detection of bla $a_{\text {OXA-51 }}$-like alleles by PCR was used to confirm the identification of the isolates as A. baumannii [43]. Antibiotic susceptibility was determined using Phoenix System, Panel NMIC/ID4 (Becton Dickinson Diagnostic Systems). Carbapenems susceptibility was confirmed by broth macrodilution procedures according to CLSI guidelines (CLSI document M100-S18). Escherichia coli ATCC 25922 and Pseudomonas aeruginosa ATCC 27853 were used as reference quality control strains of in vitro susceptibility tests. An isolate was defined as multidrug resistant if resistant to at least three classes of antibiotics commonly used in the treatment of A. baumannii infections.

\section{Characterization of -lactamases}

Analytical isoelectric focusing (IEF) of crude extracts, visualization of $\beta$-lactamase bands by nitrocefin, and detection of their activity by a substrate overlaying procedure were performed as described [44]. Known producers of various $\beta$-lactamases (TEM-1, TEM-2, TEM-7, TEM-8, TEM-9, TEM-12, SHV-1, SHV-2 and SHV-5) were used as controls. PCR amplification of $b l a_{\mathrm{OXA}-51}$ and of $b l a_{\mathrm{OXA}-10^{-}}$ like alleles was carried out with primers OXA-51-F (5'CTCTTACTTATMACAAGCGC-3') and OXA-51-R (5'CGAACAGAGCTAGRTATTC-3') (for $b l a_{\text {OXA-51 }}$ ) and with primers OXA-10-F (5'-GTCTTTCGAGTACGGCATTA-3') and OXA-10-R (5'-ATTTTCTTAGCGGCAACTTAC-3') for $b l a_{\text {OXA-10-like [45]. The PCR amplicons of } b l a_{\text {OXA-51 }} \text { and }}$ $b l a_{\text {OXA-10 }}$ genes were purified using the kit Quantum Prep PCR Kleen Spin Columns (BioRad) and subjected to direct sequencing. PCR products were sequenced on both strands with an Applied Biosystems sequencer. The nucleotide sequences were analysed with the BLAST program.

\section{Genotyping of A. baumannii isolates}

Genetic relatedness among A. baumanni isolates was investigated by pulsed-field gel electrophoresis (PFGE): genomic DNA was digested with ApaI restriction enzyme and restricted fragments were separated on a CHEF-DR II apparatus (Bio-Rad) for $20 \mathrm{~h}$ at $14^{\circ} \mathrm{C}$. Bacteriophage $\lambda$ concatemers were used as DNA size markers. DNA restriction patterns of scanned gel pictures were interpreted following cluster analysis with Fingerprinting II version 3.0 software (Bio-Rad) using the unweighted pair-group method with arithmetic averages (UPGMA). The Dice correlation coefficient was used with a $1.2 \%$ position tolerance to analyse the similarities of the banding patterns. Only bands larger than $48 \mathrm{~Kb}$ were considered for the analysis. Isolates showing more than three DNA fragment differences and a similarity of $<80 \%$ were considered to represent different PFGE types, while isolates with less than three fragment differences and a similarity of $>80 \%$ were considered as belonging to the same PFGE subtype, following the criteria for genetic characterization using PFGE described in the literature $[23,46,47]$. A. baumannii RUH875 and RUH134 were used as reference strains representative of the European clonal lineages I and II, respectively $[20,48]$.

\section{Biofilm formation assays and determination of EPS production}

Biofilm formation in microtiter plates was determined as described [49]. Bacterial cells were grown overnight in microtiter plates $(0.2 \mathrm{ml})$ either at $30^{\circ} \mathrm{C}$ or $37^{\circ} \mathrm{C}$. Bacterial growth in the liquid culture was determined by optical density at $600 \mathrm{~nm}\left(\mathrm{OD}_{600 \mathrm{~nm}}\right)$ and the liquid culture was removed. Microtiter plates were washed with $0.1 \mathrm{M}$ phosphate buffer ( $\mathrm{pH} 7.0)$, and the biofilm cells attached to the microtiter plate wells were stained for $20 \mathrm{~min}$ with $1 \%$ crystal violet (CV) in ethanol, washed, and dried. Crystal violet staining was visually assessed and the microtiter plates were scanned. For semi-quantitative determination of biofilms, CV-stained cells were resuspended in either $0.2 \mathrm{ml}$ of $70 \%$ ethanol. The absorbance at $600 \mathrm{~nm}\left(\mathrm{Abs}_{600}\right.$ $\mathrm{nm}$ ) of the resuspended CV was determined and normalized to the $\mathrm{OD}_{600 \mathrm{~nm}}$ of the corresponding grown cell density: this value corresponds to the "adhesion units". To test biofilm sensitivity to cellulase, bacterial cultures were grown in the presence of cellulase from Trichoderma reesei ATCC 26921 (5 mg/ml, 700 U/ml, Sigma). For detection of cellulose production by binding to the fluorescent dye Calcofluor (CF), bacteria were grown overnight in a microtiter plate, and the cultures were spotted, using a replicator, on solid media to which $0.005 \%$ Calcofluor (for CF medium) was added after autoclaving. Bacteria were grown for $18-20 \mathrm{~h}$ at $30^{\circ} \mathrm{C}$; staining was better detected after $24-48 \mathrm{~h}$ of additional incubation at $4^{\circ} \mathrm{C}$. 


\section{SDS-PAGE analysis of membrane proteins}

A. baumannii cultures $(100 \mathrm{ml})$ were grown in defined $\mathrm{M} 9$ medium, supplemented with $0.02 \%$ peptone and $0.01 \%$ yeast extract, to which $0.2 \%$ glucose was added as main carbon source (M9Glu/sup, [27]). Cultures were grown at $30^{\circ} \mathrm{C}$ up to $0.1 \mathrm{OD}_{600 \mathrm{~nm}}$ prior to addition of $0.125 \mu \mathrm{g} / \mathrm{ml}$ imipenem (1/4 the MIC). Both control and treated cultures were harvested 3 hours after imipenem addition, at an $\mathrm{OD}_{600 \mathrm{~nm}}>1.0$. Bacterial cells were harvested by centrifugation at $4,000 \times \mathrm{g}$ for $10 \mathrm{~min}$ at $4{ }^{\circ} \mathrm{C}$ and washed with 5 ml $0.1 \mathrm{M}$ phosphate buffer $\mathrm{pH} 7.0$ (PB). The pellet was resuspended in $2 \mathrm{ml} \mathrm{PB}$ with addition of $100 \mu \mathrm{g} / \mathrm{ml}$ lysozyme and $1 \mathrm{mM}$ EDTA pH 8.0 and incubated at room temperature for 10 minutes. Cells were disintegrated using a French Press and centrifuged as above to remove unbroken cells. The low-speed centrifugation supernatant was then centrifuged at $30,000 \times \mathrm{g}$ for 30 minutes at $4{ }^{\circ} \mathrm{C}$ to separate the cytoplasm (supernatant) and the membrane fraction (pellet). The pellet was resuspended in $1 \mathrm{ml}$ of PB. Protein concentrations were determined and $25 \mu \mathrm{g}$ of total proteins was loaded onto a $10 \%$ sodium dodecyl sulfate-polyacrylamide gel (SDS-PAGE). Bands of interest were excised from the gel and the corresponding proteins were identified by matrix-assisted laser desorption ionization-time of flight (MALDI-TOF) analysis of the peptide generated by in-gel trypsin digestion ([35]; performed by CEINGE, University of Naples, Italy http:// www.ceinge.unina.it/).

\section{Measurement of gene expression by Real Time-PCR}

Gene expression determination was performed using Real Time-PCR as previously described [29]. RNA was extracted from bacterial cultures grown as for membrane protein extraction. Production of cDNAs was obtained by reverse transcription using $1 \mu \mathrm{g}$ total RNA, along with negative control samples incubated without reverse transcriptase. Primer sequences for genes of interest were designed based on the available genome sequences for $A$. baumannii and were tested in PCR experiments on A. baumannii SMAL genomic DNA to verify the presence of the gene and the correctness of the expected products. Primer sequences were as follows: fchR_for: 5'-ACGTCAAGCGGTTGCTCCAT-3', fchR_rev: 5'-CCTGTAATCGGGTCTGTTGG-3', tonB_for: 5'-ATGGCAAGATACCGATGCCC3', tonB_rev: 5'-CCGATATCTTCGCTTGAGCG-3', csuC_for: 5'-GCCCGCCTGTAGCCAAAATT-3', csuC_rev: 5'-GAAGCATCTTGCTCGTTGCC-3', csuE_for: 5'-TAGCGGGCCTGATGGCAATT-3', csuE_rev: 5'-ACCCAGGGCTCTCAAAGAAG-3', 16S_for: 5'TGTCGTCAGCTCGTGTCGTGA-3', 16S_rev: 5'-TGATGACTTGACGTCGTCCCC-3'. Each Real Time PCR experiment was performed in triplicate and included negative control samples, which never showed significant threshold cycles. The relative transcript amounts were determined using $16 \mathrm{~S}$ rRNA as the reference gene ([ $\left[\mathrm{Ct}_{\mathrm{Gene}}\right.$ of interest $\left.-\mathrm{Ct}_{16 \mathrm{~S}}\right]=\Delta \mathrm{Ct}$ value). The results are the average of at least three independent experiments showing standard deviations $\leq 10 \%$.

\section{Other methods}

Resistance to desiccation was performed as described in [29]. Sensitivity to oxidative stress was determined by treatment with hydrogen peroxide $\left(\mathrm{H}_{2} \mathrm{O}_{2}\right)$, as described previously [50]. Transmission electron microscopy analysis was performed as described [51].

\section{Authors' contributions}

EN and RM performed the genetic characterization of the isolates. LS and GF carried out experimental work on adhesion factors. EG and AN performed the initial isolation of A. baumannii. LP supervised the genetic characterization of the isolates. PL supervised the experiments related to the identification of the adhesion factors and wrote the manuscript, which was revised and approved by all authors.

\section{Acknowledgements}

We would like to thank M. Spalla for her excellent technical collaboration and L. Dolzani for providing A. baumannii strains RUHI34 and RUH875.

This work was supported by "Programmi di Ricerca di Interesse Nazionale" (PRIN 2008) from the Italian Ministry for University and Research.

\section{References}

I. Dijkshoorn L, Nemec A, Seifert H: An increasing threat in hospitals: multidrug-resistant Acinetobacter baumannii. Nat Rev Microbiol 2007, 5:939-95I.

2. Naiemi NA, Duim B, Savelkoul PH, Spanjaard L, de Jonge E, Bart A, Vandenbroucke-Grauls CM, de Jong MD: Widespread transfer of resistance genes between bacterial species in an intensive care unit: implications for hospital epidemiology. J Clin Microbiol 2005, 43:4862-4864.

3. Fournier PE, Richet H: The epidemiology and control of Acinetobacter baumannii in health care facilities. Clin Infect Dis 2006, 42:692-699.

4. Poirel L, Nordmann P: Genetic structures at the origin of acquisition and expression of the carbapenem-hydrolyzing oxacillinase gene bla $a_{\mathrm{OX} A-58}$ in Acinetobacter baumannii. Antimicrob Agents Chemother 2006, 50: $1442-1448$.

5. Bou G, Oliver A, Martinez-Beltran J: OXA-24, a novel class D $\beta$ lactamase with carbapenemase activity in an Acinetobacter baumannii clinical strain. Antimicrob Agents Chemother 2000, 44: I556-I56I.

6. Towner KJ, Levi K, Vlassiadi M, ARPAC Steering Group: Genetic diversity of carbapenem-resistant isolates of Acinetobacter baumannii in Europe. Clin Microbiol Infect 2008, 14:161-167.

7. Heritier C, Poirel L, Nordmann P: Cephalosporinase overexpression resulting from insertion of ISAbal in Acinetobacter baumannii. Clin Microbiol Infect 2006, I2: I23-130.

8. Turton JF, Ward ME, Woodford N, Kaufmann ME, Pike R, Livermore DM, Pitt TL: The role of ISAba I in expression of OXA carbapenemase genes in Acinetobacter baumannii. FEMS Microbiol Lett 2006, 258:72-77.

9. Wisplinghoff $H$, Schmitt $R$, Wohrmann A, Stefanik D, Seifert $H$ : Resistance to disinfectants in epidemiologically defined clinical isolates of Acinetobacter baumannii. J Hosp Infect 2007, 66: $174-181$

10. Jawad A, Seifert H, Snelling AM, Heritage J, Hawkey PM: Survival of Acinetobacter baumannii on dry surfaces: comparison of outbreak and sporadic isolates. J Clin Microbiol 1998, 36: I938-194I.

II. Gibson DL, White AP, Snyder SD, Martin S, Heiss C, Azadi P, Surette $M$, Kay W: Salmonella produces an O-antigen capsule regu- 
lated by AgfD and important for environmental persistence. J Bacteriol 2006, 188:7722-7730.

12. King LB, Swiatlo E, Swiatlo A, McDaniel LS: Serum resistance and biofilm formation in clinical isolates of Acinetobacter baumannii. FEMS Immunol Med Microbiol 2009, 55:4|4-42I.

13. Rodríguez-Baño J, Martí S, Soto S, Fernández-Cuenca F, Cisneros JM, Pachón J, Pascual A, Martínez-Martínez L, McQueary C, Actis LA, Vila J, Spanish Group for the Study of Nosocomial Infections (GEIH): Biofilm formation in Acinetobacter baumannii: associated features and clinical implications. Clin Microbiol Infect 2008, I4:276-278.

14. Wroblewska MM, Sawicka-Grzelak A, Marchel H, Luczak M, Sivan A Biofilm production by clinical strains of Acinetobacter baumannii isolated from patients hospitalized in two tertiary care hospitals. FEMS Immunol Med Microbiol 2008, 53: I40-I 44.

15. Sechi LA, Karadenizli A, Deriu A, Zanetti S, Kolayli F, Balikci E, Vahaboglu H: PER-I type beta-lactamase production in Acinetobacter baumannii is related to cell adhesion. Med Sci Monit 2004, I0:BR I80-I84.

16. Lee HW, Koh YM, Kim J, Lee JC, Lee YC, Seol SY, Cho DT, Kim J: Capacity of multidrug-resistant clinical isolates of Acinetobacter baumannii to form biofilm and adhere to epithelial cell surfaces. Clin Microbiol Infect 2008, 14:49-54.

17. Tomaras AP, Dorsey CW, Edelmann RE, Actis LA: Attachment to and biofilm formation on abiotic surfaces by Acinetobacter baumannii: involvement of a novel chaperone-usher pili assembly system. Microbiology 2003, I 49:3473-3484.

18. Loehfelm TW, Luke NR, Campagnari AA: Identification and characterization of an Acinetobacter baumannii biofilm-associated protein. J Bacteriol 2008, 190: 1036-1044.

19. Gaddy YA, Tomaras A, Actis LA: The Acinetobacter baumanni 19606 OmpA protein plays a role in biofilm formation on abiotic surfaces and in the interaction of this pathogen with eukaryotic cells. Infect Immun 2009, 77:3150-3160.

20. Nemec A, Dijkshoorn L, Reijden T van der: Long-term predominance of two pan-European clones among multi-resistant Acinetobacter baumannii strains in the Czech Republic. J Med Microbiol 2004, 53:147-I53.

21. van Dessel H, Dijkshoorn L, Reijden T van der, Bakker N, Paauw A, Broek $P$ van den, Verhoef J, Brisse S: Identification of a new geographically widespread multi-resistant Acinetobacter baumannii clone from European hospitals. Res Microbiol 2004, I55: I05-II2.

22. Bratu S, Landman D, Martin DA, Georgescu C, Quale J: Correlation of antimicrobial resistance with beta-lactamases, the OmpA-like porin, and efflux pumps in clinical isolates of Acinetobacter baumannii endemic to New York City. Antimicrob Agents Chemother 2008, 52:2999-3005.

23. Turton JF, Kaufmann ME, Warner M, Coelho J, Dijkshoorn L, Reijden $T$ van der, Pitt TL: A prevalent multiresistant clone of Acinetobacter baumannii in Southeast England. J Hosp Infect 2004, 58:170-179.

24. Turton JF, Gabriel SN, Valderrey C, Kaufmann ME, Pitt TL: Use of sequence-based typing and multiplex PCR to identify clonal lineages of outbreak strains of Acinetobacter baumannii. Clin Microbiol Infect 2007, I 3:807-8I5.

25. Mueller RS, Beyhan S, Saini SG, Yildiz FH, Bartlett DH: Indole acts as an extracellular cue regulating gene expression in Vibrio cholerae. J Bacteriol 2009, I 9 1:3504-35 |6.

26. Trappetti C, Kadioglu A, Carter M, Hayre J, lannelli F, Pozzi G, Andrew PW, Oggioni MR: Sialic Acid: a preventable signal for pneumococcal biofilm formation colonization, and invasion of the host. J Infect Dis 2009, 199: I 497-I505.

27. Brombacher E, Baratto A, Dorel C, Landini P: Gene expression regulation by the curli activator CsgD protein: modulation of cellulose biosynthesis and control of negative determinants for microbial adhesion. J Bacteriol 2006, 188:2027-2037.

28. Perrin C, Briandet R, Jubelin G, Lejeune $P$, Mandrand Berthelot MA, Rodrigue A, Dorel C: Nickel promotes biofilm formation by Escherichia coli K-12 strains that produce curli. Appl Environ Microbiol 2009, 75: I723-1733.

29. Gualdi L, Tagliabue L, Bertagnoli S, leranò T, De Castro C, Landini P. Cellulose modulates biofilm formation by counteracting curli-mediated colonization of solid surfaces in Escherichia coli. Microbiology 2008, I54:2017-2024.
30. Zogaj X, Nimtz M, Rohde M, Bokranz W, Romling U: The multicellular morphotypes of Salmonella typhimurium and Escherichia coli produce cellulose as the second component of the extracellular matrix. Mol Microbiol 200 I, 39: I 452-I 463.

31. Solano C, García B, Valle J, Berasain C, Ghigo JM, Gamazo C, Lasa I: Genetic analysis of Salmonella enteritidis biofilm formation: critical role of cellulose. Mol Microbiol 2002, 43:793-808.

32. Spiers AJ, Bohannon J, Gehrig SM, Rainey PB: Biofilm formation at the air-liquid interface by the Pseudomonas fluorescens SBW25 wrinkly spreader requires an acetylated form of cellulose. Mol Microbiol 2003, 50:15-27.

33. Hoffman LR, D'Argenio DA, McCoss MJ, Zhang Z, Jones RA, Miller SI: Aminoglycoside antibiotics induce bacterial biofilm formation. Nature 2005, 436: I I7I-II75.

34. Lewis K: Multidrug tolerance of biofilms and persister cells. Curr Top Microbiol Immunol 2008, 322: I07-I3I.

35. Chen X, Smith LM, Bradbury EM: Site-specific mass tagging with stable isotopes in proteins for accurate and efficient protein identification. Anal Chem 2000, 72: I I34-I I43.

36. Banin E, Vasil ML, Greenberg EP: Iron and Pseudomonas aeruginosa biofilm formation. Proc Natl Acad Sci USA 2005, 102: I 1076-II08I.

37. Johnson M, Cockayne A, Morrisey JA: Iron-regulated biofilm formation in Staphylococcus aureus Newman requires ica and the secreted protein Emp. Infect Immun 2008, 76:1756-1765.

38. Leid JG, Willson C], Shirtliff ME, Hassett DJ, Parsek MR, Jeffers AK The exopolysaccharide alginate protects Pseudomonas aeruginosa biofilm bacteria from IF $\mathrm{N}-\gamma$-mediated macrophage killing. J Immunol 2005, I75:75। 2-75 I8.

39. Crosa JH, Walsh CT: Genetics and assembly line enzymology of siderophore biosynthesis in bacteria. Microbiol Mol Biol Rev 2002, 66:223-249.

40. Vallenet D, Nordmann P, Barbe V, Poirel L, Mangenot S, Bataille E, Dossat C, Gas S, Kreimeyer A, Lenoble P, Oztas S, Poulain J, Segurens B, Robert C, Abergel C, Claverie JM, Raoult D, Médigue C, Weissenbach J, Cruveiller S: Comparative analysis of Acinetobacters: three genomes for three lifestyles. PLoS ONE 2008, 3:el805.

4I. de Breij A, Gaddy J, Meer J van der, Koning R, Koster A, Broek P van den, Actis L, Nibbering P, Dijkshoorn L: CsuA/BABCDE-dependent pili are not involved in the adherence of Acinetobacter baumannii ATCC19606(T) to human airway epithelial cells and their inflammatory response. Res Microbiol 2009, 160:213-218.

42. Anderson GG, Moreau-Marquis S, Stanton BA, O'Toole GA: In vitro analysis of tobramycin-treated Pseudomonas aeruginosa biofilms on cystic fibrosis-derived airway epithelial cells. Infect Immun 2008, 76: | 423-I 433.

43. Héritier C, Poirel L, Fournier PE, Claverie JM, Raoult D, Nordmann $P$ : Characterization of the naturally occurring oxacillinase of A. baumannii. Antimicr Agents Chemother 2005, 49:4174-4I79.

44. Pagani L, Migliavacca R, Pallecchi L, Matti C, Giacobone E, Amicosante G, Romero E, Rossolini GM: Emerging extended-spectrum $\beta$ lactamases in Proteus mirabilis. I Clin Microbiol 2002, 40:1549-1552.

45. Vahaboglu H, Ozturk R, Akbal H, Saribas S, Tansel O, Coskunkan F: Practical approach for detection and identification of OXA10-derived Ceftazidime-hydrolyzing extended-spectrum $\beta$ lactamases. J Clin Microbiol 1998, 36:827-829.

46. Zarrilli R, Casillo R, Di Popolo A, Tripodi MF, Bagattini M, Cuccurullo S, Crivaro V, Ragone E, Mattei A, Galdieri N, Triassi M, Utili R: Molecular epidemiology of a clonal outbreak of multidrugresistant Acinetobacter baumannii in a university hospital in Italy. Clin Microbiol Infect 2007, 13:48I-489H.

47. Seifert H, Dolzani L, Bressan R, Reijden T Van Der, Van Strijen B, Stefanik D, Heersma H, Dijkshoorn L: Standardization and interlaboratory reproducibility assessment of pulsed-field gel electrophoresis-generated fingerprints of Acinetobacter baumannii. J Clin Microbiol 2005, 43:4328-4335.

48. Dijkshoorn L, Aucken H, Gerner-Smidt P, Janssen P, Kaufmann ME, Garaizar J, Ursing J, Pitt TL: Comparison of outbreak and non outbreak Acinetobacter baumannii strains by genotypic and phenotypic methods. J Clin Microbiol I996, 34:1519-I525.

49. Dorel C, Vidal O, Prigent-Combaret C, Vallet I, Lejeune P: Involvement of the Cpx signal transduction pathway of $E$. coli in biofilm formation. FEMS Microbiol Lett 1999, 178:169-175. 
50. Volkert MR, Hajec LI, Matijasevic Z, Fang FC, Prince R: Induction of the Escherichia coli aid $B$ gene under oxygen-limiting conditions requires a functional rpoS (katF) gene. J Bacteriol 1994, 1 76:7638-7645.

5I. Prigent-Combaret C, Prensier G, Le Thi TT, Vidal O, Lejeune P, Dorel C: Developmental pathway for biofilm formation in curli-producing Escherichia coli strains: role of flagella curli and colanic acid. Environ Microbiol 2000, 2:450-464.

52. Smith MG, Gianoulis TA, Pukatzki S, Mekalanos J], Ornston LN, Gerstein M, Snyder M: New insights into Acinetobacter baumannii pathogenesis revealed by high-density pyrosequencing and transposon mutagenesis. Genes Dev 2007, 2 I:60 I-6I4.

Publish with Bio Med Central and every scientist can read your work free of charge

"BioMed Central will be the most significant development for disseminating the results of biomedical research in our lifetime. "

Sir Paul Nurse, Cancer Research UK

Your research papers will be:

- available free of charge to the entire biomedical community

- peer reviewed and published immediately upon acceptance

- cited in PubMed and archived on PubMed Central

- yours - you keep the copyright

Submit your manuscript here:

http://www.biomedcentral.com/info/publishing_adv.asp
BioMedcentral 